\title{
Phenotypic differences in familial adenomatous polyposis based on APC gene mutation status
} K Heinimann, B Müllhaupt, W Weber, M Attenhofer, R J Scott, M Fried, S Martinoli,
Hj Müller, Z Dobbie all gene carriers presenting with colonic polyposis by the fourth decade. Affected individuals develop from a few dozen to several thousand adenomatous polyps in the colon and rectum, usually starting in the second or third decade of life. If left untreated, some of these polyps develop into CRC during the fourth or fifth decade of life. ${ }^{2}$ Phenotypic heterogeneity, however, is a typical characteristic of this disease. The attenuated form of APC (AAPC) ${ }^{3}$ or the flat adenoma syndrome ${ }^{4}$ has been characterised by a low and highly heterogeneous number of colonic polyps and later age of onset. In contrast, other manifestations in addition to colonic polyps may occur, which include polyps of the upper gastrointestinal tract, desmoids, osteomas, fibromas, and lipomas.

The molecular mechanisms underlying disease development have been intensively studied within the past few years; however, they seem to be more heterogeneous than initially believed. FAP has been considered to be a typical monogenic disease caused by germline mutations within the adenomatous polyposis coli (APC) gene which was first localised to chromosome 5q21-22 and then identified in 1991..$^{5-9}$ However, phenotypic heterogeneity in FAP patients cannot be completely explained by different mutations within the APC gene and other genetic factors can modify disease expression as suggested by various mouse models of FAP. ${ }^{10}{ }^{11}$

Additionally, despite the application of several screening techniques, mutation studies worldwide fail to identify germline mutations within the APC gene in about $20-50 \%$ of all FAP patients. ${ }^{12-21}$ Several reasons could account for this failure. Firstly, none of the methods are sensitive enough to detect all mutations, although the combination of several different techniques results in a relatively high detection rate. Secondly, to our knowledge, none of the research groups currently includes the analysis of regulatory regions of the APC gene or quantitative tests of APC gene expression in their screening procedures. Mutations within these regions, which would lead to altered gene expression, might account for some of the APC negative cases. Additionally, FAP families with no genetic linkage to the APC locus have been described, ${ }^{22}{ }^{23}$ supporting the hypothesis that other genes might be involved in the development of FAP or might lead to a similar clinical phenotype.

In the present study, the phenotypic characteristics were analysed in 161 affected individuals from 50 clinically diagnosed Swiss FAP
Accepted for publication 18 May 1998
Familial adenomatous polyposis (FAP) has been recognised for over 100 years. It is an autosomal dominantly inherited disease which accounts for approximately $1 \%$ of all colorectal cancer (CRC) patients. The population incidence of FAP, according to the Danish Register, which is probably the most complete national register, seems to be 1 in $7000^{1}$ and affects both sexes equally. Characteristically, FAP has a very high penetrance with virtually 


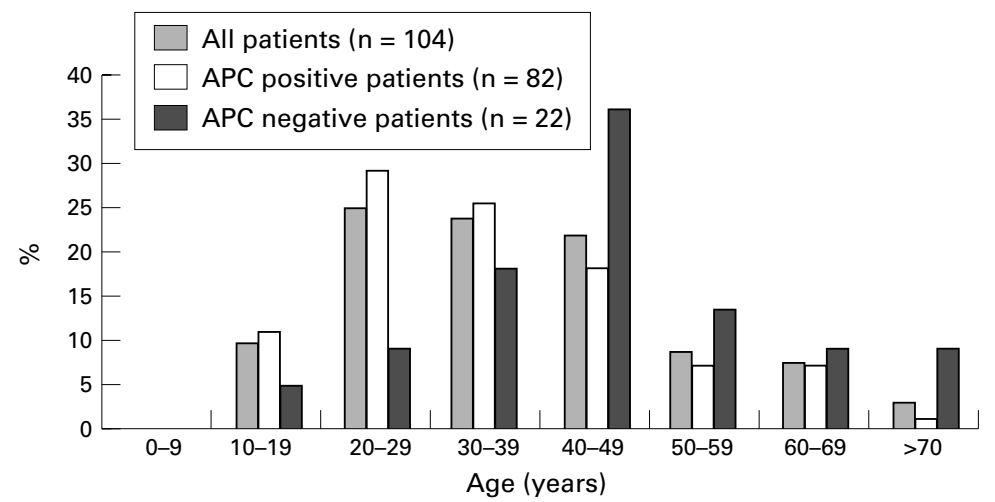

Figure 1 Age at diagnosis of colonic polyposis in FAP patients.

families and compared according to their APC mutation status. The aim was to delineate differences between APC positive and APC negative patients in order to characterise further possible mechanisms which might lead to colonic polyposis in kindreds without an APC mutation.

\section{Patients and methods}

FAMILIAL ADENOMATOUS POLYPOSIS PATIENTS In this study, 161 patients from 50 Swiss FAP families, referred to our department from all parts of Switzerland during the time period 1993-1997 with the clinical diagnosis of FAP, were investigated. Clinical information was obtained from medical records, where available, and from interviews with physicians and/or patients. Patients undergoing colonoscopy were prepared with 3 litres orally of a polyethylene glycol solution. Colonoscopy was performed according to standard protocols without dye spray.

MUTATION ANALYSIS OF THE APC GENE

Mutation analysis of the whole coding region of the APC gene was performed using the combination of the protein truncation test (PTT), single stranded conformation polymorphism (SSCP), and direct DNA sequencing. These methods were performed according to published protocols. ${ }^{24-26}$

FAP families with detected APC gene mutations were ascertained as APC positive while kindreds without detected mutations were included in the APC negative group.

PHENOTYPIC AND STATISTICAL ANALYSIS

Both groups of FAP families, APC positive and APC negative, were compared for sex ratio, age at diagnosis, polyp histology and number, cancer occurrence, and extracolonic manifestations. The data were compared with the Swiss population tables on CRC from the Swiss Cancer Registries' Association database. Statistical evaluation was performed using the $\chi^{2}$ test, Fisher's exact test, and Student's $t$ test.

\section{Results}

In this study, 50 Swiss FAP families were investigated for APC gene mutations and evaluated for differences in disease expression according to their mutation status.
In 36 families (72\%), mutation analysis revealed germline mutations in the APC gene (APC positive group). Mutations were found at codons 99, 151, 169, 232, 498, 793, 805, 849, 935,1061 (three families), 1062, 1135, 1191, 1193, 1285, 1309 (two families), 1324, 1373, $1393,1403,1414,1450,1465$, and 1987 (10 families). Nine families with a mutation in codon 1987 were found to be of common ancestry (founder effect dating back to the eighteenth century). ${ }^{27}$ In 14 families (28\%) no APC mutation was identified after screening the entire coding region of the gene (APC negative group). Based on pedigree data, there was no indication of the presence of HNPCC in any of these families.

Within the 50 FAP families, 161/384 (42\%) individuals were affected with either colonic polyposis $(n=122)$, cancer of the gastrointestinal tract only $(n=36)$, or extracolonic manifestations only $(n=3)$. In the APC positive group 93 patients had colonic polyposis, 24 cancer of the gastrointestinal tract only, and three extracolonic manifestations only, resulting in 120/300 (40\%) affected individuals. In the APC negative group, $41 / 84(48.8 \%)$ were affected with colonic polyposis $(n=29)$ or cancer of the gastrointestinal tract only $(n=12)$; none had extracolonic lesions only.

The overall sex ratio among affected individuals was $55 \%: 45 \%$ (male:female) with similar ratios in the APC positive and APC negative groups (57\%:43\% and 51\%:49\%, respectively).

\section{COLONIC POLYPOSIS}

In $104 / 122(85 \%)$ patients with colonic polyposis the age at diagnosis could be established from their medical records. The mean (SD) age was 37.3 (14.8) years (range 11-73). Interestingly, a comparison between the two groups revealed a statistically significant difference in age distribution, with an average (SD) age at diagnosis of 35.2 (13.8) years (range $11-70 ; 95 \%$ confidence interval (CI) 32.2-38.2; median 33) in the APC positive $(n=82)$ and 45.3 (15.7) years (range 13-73; 95\% CI 38.7-51.9; median 46) in the APC negative group $(n=22)(p<0.01)$. When only index patients of both groups $(n=32$ and $\mathrm{n}=14$, respectively) were compared, the difference in mean age at diagnosis (34.6 versus 48.7 years) remained statistically significant $(\mathrm{p}<0.01)$. The peak incidence of polyposis in the APC positive group occurred in the third and fourth decade, whereas in the APC negative group it was shifted towards the fourth and fifth decade (fig 1).

From 48 patients data were available on polyp histology: $48 \%$ were tubular, $46 \%$ tubulovillous, and $6 \%$ villous adenomas, with no differences between the APC positive and APC negative groups. From the endoscopic records, the number of polyps at diagnosis could be determined in 33 patients. Nine patients (five APC positive and four APC negative) had less than 100 polyps and 24 patients (19 APC positive and five APC negative) displayed more than 100 colorectal polyps. No correlation between polyp number and either age at diagnosis or mutation site was found. In contrast to 


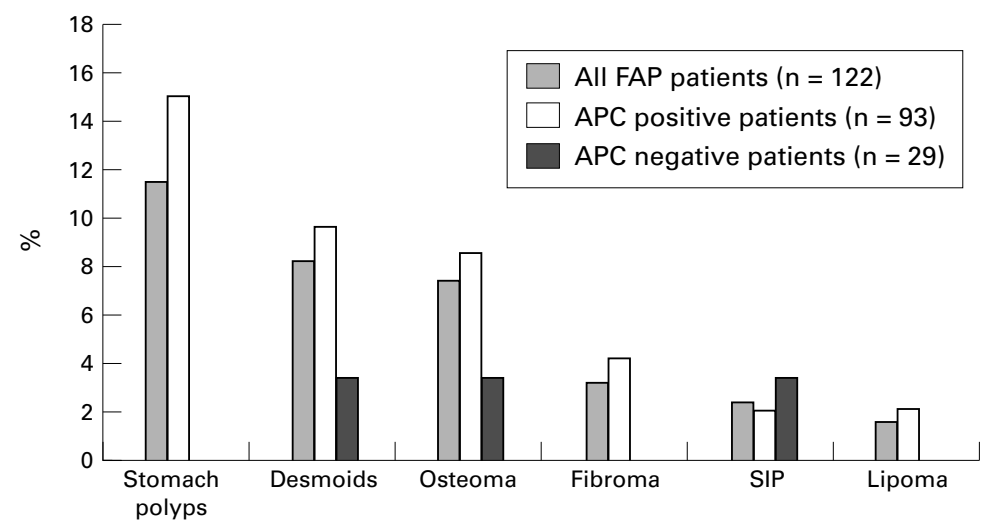

Figure 2 Percentage of extracolonic manifestations in 27 FAP patients. SIP, small intestinal polyps. whereas the sex ratio for the remaining EM was virtually $1: 1$. Nine patients with stomach polyps harboured the same mutation at codon 1987 with a sex ratio 8:1 (male:female).

A statistically significant difference $(\mathrm{p}<0.03)$ was found with respect to stomach polyps occurring only in APC positive patients (see fig 2). Although not statistically significant, desmoid tumours (four intra-abdominal, two extra-abdominal, three site unknown) also tended to be much more frequent in the APC positive group.

With the exception of three patients with stomach polyps (mutation in codons 805, 1191, and 1373) and one with osteoma (codon 1309), all other extracolonic manifestations were associated with an APC mutation located beyond codon 1403. Desmoid cases were rather clustered in families and did not occur in patients with mutations prior to codon 1403.

APC negative individuals, APC positive tients tended to have more than 100 polyps at diagnosis.

CANCER OCCURRENCE

Among the 161 affected persons, 65 (40\%) developed cancer. Twenty nine cancer patients (22 APC positive and seven APC negative) also had clinically verified colonic polyposis. In 36 patients (24 APC positive and 12 APC negative), no clinical record of the presence of colonic polyposis could be found.

Fifty four $(83 \%)$ tumours originated from the gastrointestinal tract. Six (9\%) patients developed another type of cancer (one case each of $\mathrm{T}$ cell lymphoma, meningeoma, rhabdomyosarcoma, brain tumour, genitourinary tract tumour, and skin tumour). The cancer site was unknown in five ( $8 \%)$ patients. The cancer distribution in all subgroups (APC positive versus APC negative, and patients with clinically verified polyposis versus patients without known polyposis) was virtually identical with the overall cancer occurrence.

For colorectal cancer, the mean (SD) age at diagnosis was 47.8 (12.6) years (range 24-80). The peak incidence of CRC was found in the fifth decade in contrast to data reported in the Swiss general population (Swiss Cancer Registries' Association database, 1996) where the peak incidence occurred in the eighth and ninth decade. Although no statistically significant difference was observed between APC positive and APC negative individuals with respect to the mean age at diagnosis, only one in 12 patients who developed cancer under the age of 40 was APC negative.

\section{EXTRACOLONIC MANIFESTATIONS}

Extracolonic manifestations (EM) were identified in 27/122 (22\%) FAP patients (21/93 APC positive and 3/29 APC negative) as shown in fig 2. Stomach polyps were the most frequent EM (33\%), followed by desmoid tumours (24\%), osteomas $(21 \%)$, fibromas (10\%), small intestinal polyps $(7 \%)$, and lipomas $(5 \%)$. In three patients (all APC positive) no colonic polyposis was found: two had stomach polyps at age 39 and 40 years, respectively, and one had a mandibular osteoma at eight years of age. Determining the sex ratio for each EM, 12/14 (86\%) patients with stomach polyps were male,

\section{Discussion}

Despite using several detection techniques, in up to $50 \%$ of FAP patients worldwide no mutation in the APC gene can be found. ${ }^{12-21}$ These patients present with common phenotypic FAP characteristics and represent a difficult problem for genetic counselling, as no presymptomatic diagnosis and phenotypic prediction can be provided.

Besides the incomplete sensitivity of the applied diagnostic methods, intronic alterations and/or mutations within the regulatory regions of the APC gene could account for the failure to identify some APC mutations. Though usually not screened in the routine APC testing, such alterations might lead to changes in gene expression. However, assuming no hot spots within this region, based on the known length of the APC promotor (about $800 \mathrm{bp}$ ) compared with the overall length of the coding sequence (about $8000 \mathrm{bp}$ ), it seems count for many FAP cases. Furthermore, as FAP families with no linkage to the APC locus exist, ${ }^{22}{ }^{23}$ other genes might give rise to a very similar phenotype.

To evaluate the possibilities described above, we divided 50 FAP kindreds according to their mutation status into APC positive (36 families, 120 patients) and APC negative (14 families, 41 patients) groups and characterised them phenotypically with respect to polyposis, cancer occurrence, and extracolonic manifestations. Due to the small size of the APC negative families, linkage analysis to the APC locus could not be performed.

Overall mean age at diagnosis for polyposis was 37.3 years which is in general agreement with data published by other groups. ${ }^{28-30}$ By comparing the APC positive and APC negative groups, however, a statistically significant difference in the mean age at diagnosis has been observed ( 35.2 and 45.3 years respectively). Furthermore, this delay of about 10 years cosegregated with a tendency to display less polyps at diagnosis in APC negative patients.

The age at diagnosis of colorectal cancer ranged between the fourth and the fifth decade. highly unlikely that promotor mutations ac- 
Debinski et al reported a 2.3 times greater risk of cancer for patients with over 100 polyps. ${ }^{31}$ In the present study, all CRC patients with known polyp numbers had more than 100 polyps at the time of diagnosis, supporting the association between a high polyp number and an increased risk of developing CRC.

The most common extracolonic features in FAP families were polyps of the upper gastrointestinal tract $(13 \%)$. In the literature, it has been reported that these lesions occur in $23-56 \%$ of FAP patients ${ }^{32-35}$ or even in up to $90 \%{ }^{30}$ However, not all of the patients in this study have been screened for upper gastrointestinal polyps, and this might result in an underestimation of the true number of cases. Remarkably, 12/14 patients with stomach polyps were men. Even when adjusted for mutation site (nine patients harboured a mutation at codon 1987) this sex disequilibrium remained. This is in contrast to observations made by Gahtan et al who reported an equal sex distribution. ${ }^{36}$ Furthermore, population based studies found no correlation between gastric polyps and sex. ${ }^{37-39}$ As the number of affected patients in our study was relatively low $(n=14)$ we cannot exclude aggregation by chance. All patients except one with upper gastrointestinal polyps were identified as APC positive FAP patients.

According to the literature, desmoids occur in approximately $4-15 \%$ of patients with FAP, a much higher frequency than in any other disease. ${ }^{32} 4041$ In the current study $8 \%$ of polyposis patients developed desmoids. Similar to other studies, desmoid cases were clustered in certain families ${ }^{40}$ and all appeared in patients with APC mutations beyond codon $1403 .{ }^{42-45}$ Similar to the findings of Giardiello et al, ${ }^{20} \mathrm{APC}$ positive patients were more likely to develop desmoids than APC negative patients.

Taken together, the APC negative group presented with milder phenotypic disease manifestations similar to those described for AAPC. ${ }^{325}{ }^{46}$ However, mutations at the 5 ' end of the APC gene which have been shown to be responsible for some of these cases, have been excluded using both SSCP and PTT.

In conclusion, our observations indicate that FAP kindreds without an identified mutation in the coding region of the APC gene display a disease phenotype which is notably different from patients with an APC mutation, suggesting that they might represent a distinct genetic category. In general, the APC negative group tended to have less severe disease with a significantly increased age at diagnosis, less colonic polyps, and fewer extracolonic manifestations. Mutations in the gene promotor as well as mutations in genes other than APC with a weaker influence on disease expression might account for this observation and should be addressed in further studies in order to reach a better understanding of FAP disease.

We thank the families and their physicians for participating in the study. We are grateful to Dr Isabelle Daigle and Daniel the study. We are grateful to Dr Isabelle Daigle and Daniel
Maier for critical review of the manuscript as well as the Swiss Maier for critical review of the manuscript as well as the Swiss
Cancer Registries' Association, in particular, Professor Fabio Levi, for providing us with Swiss population based disease inciLevi, for providing us with Swiss population based disease inci-
dence figures. This work was supported by grants from the Swiss National Foundation 3200-049310.96 and the Cancer
League of both Cantons of Basel.

1 Bulow S. The Danish Polyposis Registry. Dis Colon Rectum 1984;27:351-5.

2 Bufill JA. Colorectal cancer genetics. Closing the gap between genotype and phenotype [editorial; comment]. Cancer 1995;76:2389-92.

3 Spirio L, Olschwang S, Groden J, et al. Alleles of the APC gene: an attenuated form of familial polyposis. Cell 1993;75:951-7

4 Lynch HT, Smyrk TC, Lanspa SJ, et al. Upper gastrointestinal manifestations in families with hereditary flat adenoma syndrome. Cancer 1993;71:2709-14.

5 Bodmer WF, Bailey CJ, Bodmer J, et al. Localization of the gene for familial adenomatous polyposis on chromosome 5 . Nature 1987;328:614-16.

6 Leppert M, Dobbs M, Scambler P, et al. The gene for familial polyposis coli maps to the long arm of chromosome 5 . Science 1987;238:1411-13.

7 Kinzler KW, Nilbert MC, Su LK, et al. Identification of FAP locus genes from chromosome 5q21. Science 1991;253: $661-5$.

8 Groden J, Thliveris A, Samowitz W, et al. Identification and characterization of the familial adenomatous polyposis coli gene. Cell 1991;66:589-600.

9 Joslyn G, Carlson M, Thliveris A, et al. Identification of deletion mutations and three new genes at the familial polyposis locus. Cell 1991;66:601-13.

10 Dietrich WF, Lander ES, Smith JS, et al. Genetic identification of Mom-1, a major modifier locus affecting Mininduced intestinal neoplasia in the mouse. Cell 1993;75: 631-9.

11 MacPhee M, Chepenik KP, Liddell RA, et al. The secretory phospholipase A2 gene is a candidate for the Mom 1 locus, major modifier of ApcMin-induced intestinal neoplasia. Cell 1995;81:957-66.

12 Miyoshi Y, Ando H, Nagase H, et al. Germ-line mutations of the APC gene in 53 familial adenomatous polyposis patients. Proc Natl Acad Sci USA 1992;89:4452-6.

13 Groden J, Gelbert L, Thliveris A, et al. Mutational analysis of patients with adenomatous polyposis: identical inactivating mutations in unrelated individuals. Am f Hum Genet 1993;52:263-72.

14 Nagase H, Nakamura Y. Mutations of the APC (adenomatous polyposis coli) gene. Hum Mutat 1993;2:425-34

15 Varesco L, Gismondi V, James R, et al. APC gene mutations in Italian familial polyposis coli patients. Cancer Detect Prev 1993;17:279-81

16 Mandl M, Paffenholz R, Friedl W, et al. Frequency of common and novel inactivating APC mutations in 202 families with familial adenomatous polyposis. Hum Mol Genet 1994;3:181-4

17 Baba S, Ando H, Nakamura Y. Identification of germ line mutation of APC gene in possible carriers of familial adenomatous polyposis (FAP). Anticancer Res 1994;14:2189-92.

18 Walpole IR, Kool DA, Edkins T, et al. Genetic counselling and gene mutation analysis in familial adenomatous polyposis in Western Australia. Med f A ust 1995;162:464-7. Armstrong JG, Davies DR, Guy SP, et al. APC mutations in
familial adenomatous polyposis families in the Northwest familial adenomatous polyposis families in

20 Giardiello FM, Petersen GM, Piantadosi S, et al. APC gene mutations and extraintestinal phenotype of familial adenomutations and extraintestinal phenotype
matous polyposis. Gut 1997;40:521-5.

21 van der Luijt RB, Khan PM, Vasen HF, et al. Molecular analysis of the APC gene in 105 Dutch kindreds with familial adenomatous polyposis: 67 germline mutations identified by DGGE, PTT, and Southern analysis. Hum Mutat 1997;9:7-16.

22 Stella A, Resta N, Gentile M, et al. Exclusion of the APC gene as the cause of a variant form of familial adenomatous polyposis (FAP). Am f Hum Genet 1993;53:1031-7.

23 Tops CM, van der Klift HM, van der Luijt RB, et al. Nonallelic heterogeneity of familial adenomatous polyposis. $\mathrm{Am}$ f Med Genet 1993;47:563-7.

24 Dobbie Z, Spycher M, Mary JL, et al. Correlation between the development of extracolonic manifestations in FAP patients and mutations beyond codon 1403 in the APC gene. F Med Genet 1996;33:274-80.

25 Dobbie Z, Spycher M, Hurliman R, et al. Mutational analysis of the first 14 exons of the adenomatous polyposis coli sis of the first 14 exons of the adenomatous poly
(APC) gene. Eur 7 Cancer 1994;30A:1709-13.

26 Powell SM, Petersen GM, Krush AJ, et al. Molecular diagnosis of familial adenomatous polyposis. $N$ Engl $f$ Med 1993;329:1982-7.

27 Scott RJ, van der Luijt R, Spycher M, et al. Novel germline APC gene mutation in a large familial adenomatous polyposis kindred displaying variable phenotypes. Gut 1995;36:731-6.

28 Morton DG, Macdonald F, Haydon J, et al. Screening practice for familial adenomatous polyposis: the potential for regional registers. Br F Surg 1993;80:255-8.

29 Iwama T, Mishima Y. Mortality in young first-degree relatives of patients with familial adenomatous polyposis. Cancer 1994;73:2065-8.

30 De Pietri S, Sassatelli R, Roncucci L, et al. Clinical and biologic features of adenomatosis coli in Northern Italy. Scand f Gastroenterol 1995;30:771-9.

31 Debinski HS, Love S, Spigelman AD, et al. Colorectal polyp counts and cancer risk in familial adenomatous polyposis. Gastroenterology 1996;110:1028-30.

32 Campbell WJ, Spence RA, Parks TG. Familial adenomatous polyposis. Br F Surg 1994;81:1722-33. 
33 Bulow S, Alm T, Fausa O, et al. Duodenal adenomatosis in familial adenomatous polyposis. DAF Project Group. Int $\mathcal{f}$ Colorectal Dis 1995;10:43-6.

34 Debinski HS, Spigelman AD, Hatfield A, et al. Upper intestinal surveillance in familial adenomatous polyposis. Eur $\mathcal{F}$ Cancer 1995;31A: 1149-53.

35 Odze RD. Epithelial proliferation and differentiation in flat duodenal mucosa of patients with familial adenomatous polyposis. Mod Pathol 1995;8:648-53.

36 Gahtan V, Nochomovitz LE, Robinson AM, et al. Gastroduodenal polyps in familial polyposis coli. Am Surg 1989;55:278-80

37 Stolte M, Sticht T, Eidt S, et al. Frequency, location, and age and sex distribution of various types of gastric polyp. Endoscopy 1994;26:659-65.

38 Archimandritis A, Spiliadis C, Tzivras M, et al. Gastric epithelial polyps: a retrospective endoscopic study of 12974 symptomatic patients. Ital f Gastroenterol 1996;28:387-90.

39 Lymptomatic patients. Ital f Gastroenterol 1996;28:387-90. Leggett BA, Young JP, Biden K, et al. Severe upper
gastrointestinal polyposis associated with sparse colonic gastrointestinal polyposis associated with sparse colonic
polyposis in a familial adenomatous polyposis family polyposis in a familial adenomatous polyposis family with 21 .

40 Gurbuz AK, Giardiello FM, Petersen GM, et al. Desmoid tumours in familial adenomatous polyposis. Gut 1994;35: 377-81.
41 Rodriguez-Bigas MA, Mahoney MC, Karakousis CP, et al. Desmoid tumors in patients with familial adenomatous polyposis. Cancer 1994;74:1270-4.

42 Gayther SA, Wells D, SenGupta SB, et al. Regionally clustered APC mutations are associated with a severe phenotype and occur at a high frequency in new mutation cases of adenomatous polyposis coli. Hum Mol Genet 1994; 3:53-6.

43 Caspari R, Olschwang S, Friedl W, et al. Familial adenomatous polyposis: desmoid tumours and lack of ophthalmic lesions (CHRPE) associated with APC mutations beyond codon 1444. Hum Mol Genet 1995;4:337-40.

44 Davies DR, Armstrong JG, Thakker N, et al. Severe Gardner syndrome in families with mutations restricted to a specific region of the APC gene. Am F Hum Genet 1995; 57:1151-8.

45 Scott RJ, Froggatt NJ, Trembath RC, et al. Familial infiltrative fibromatosis (desmoid tumours) (MIM135290) caused by a recurrent 3' APC gene mutation. Hum Mol Genet 1996;5:1921-4.

46 Giardiello FM, Brensinger JD, Luce MC, et al. Phenotypic expression of disease in families that have mutations in the 5 ' region of the adenomatous polyposis coli gene. Ann Intern Med 1997;126:514-19. 